Review

\title{
Two Effective Routes for Removing Lineage Restriction Roadblocks: From Somatic Cells to Hepatocytes
}

\section{Chenxia $\mathrm{Hu}$ and Lanjuan $\mathrm{Li}$ *}

Collaborative Innovation Center for Diagnosis and Treatment of Infectious Diseases, State Key Laboratory for Diagnosis and Treatment of Infectious Diseases, School of Medicine, First Affiliated Hospital, Zhejiang University, Hangzhou 310058, China;

E-Mail: 11318093@zju.edu.cn

* Author to whom correspondence should be addressed; E-Mail: 1jli@zju.edu.cn; Tel.: +86-571-8723-6759; Fax: +86-571-8723-6755.

Academic Editor: Wenbin Deng

Received: 3 August 2015 / Accepted: 24 August 2015 / Published: 1 September 2015

\begin{abstract}
The conversion of somatic cells to hepatocytes has fundamentally re-shaped traditional concepts regarding the limited resources for hepatocyte therapy. With the various induced pluripotent stem cell (iPSC) generation routes, most somatic cells can be effectively directed to functional stem cells, and this strategy will supply enough pluripotent material to generate promising functional hepatocytes. However, the major challenges and potential applications of reprogrammed hepatocytes remain under investigation. In this review, we provide a summary of two effective routes including direct reprogramming and indirect reprogramming from somatic cells to hepatocytes and the general potential applications of the resulting hepatocytes. Through these approaches, we are striving toward the goal of achieving a robust, mature source of clinically relevant lineages.
\end{abstract}

Keywords: induced pluripotent stem cells; differentiation; reprogramming; hepatocyte; in vitro; in vivo 


\section{Introduction}

As the largest organ in the human body, the liver performs multiple metabolic functions, including detoxification, glucose metabolism, plasma protein synthesis, and bile production [1]. These metabolic functions are supported by sinusoidal endothelial cells, hepatic stellate cells, Kupffer cells, and cholangiocytes. These cells cooperate to regulate hepatocyte function and maintain homeostasis in humans or animals. However, because of the various causes of hepatic injury, the number of people living with end-stage liver disease is increasing rapidly, and more than one million people die each year from acute and chronic liver diseases across the globe [2]. The need for liver transplantation has increased rapidly, accompanied by an ongoing shortage of donor livers. To reduce the demand for tissue, hepatocyte transplantation has been substituted for whole organ transplantation. However, this approach has not been widely adopted due to a variety of technical reasons, including the inability to monitor graft health and frequent rejection signs [3]. Hepatocytes proliferate poorly in vitro, although microenvironments that promote their multiplication are being intensively but unsuccessfully investigated.

Pluripotent stem cells, which can self-renew, maintain genetic stability, and possess multilineage potential in vitro, have attracted attention worldwide. Cell lines derived from hepatocellular carcinoma or generated through SV40 large T antigen transformation have enabled the expansion and creation of in vitro model systems [4], but their malignant backgrounds and requirements for non-physiological manipulations have inhibited their clinical usage. Embryonic stem cells (ESCs) derived from the inner cell mass of mammalian blastocysts have been deemed as ideal candidates for regenerative medicine but have resulted in ethical concerns and incompatibility with the immune system. Adult tissue-derived stem cells, which are plentiful without using embryonic materials, can be easily extracted but possess innate limitations in stem cell potency and therapeutic potential. Induced pluripotent stem cells (iPSCs) were first generated by Yamanaka and colleagues following the forced expression of four transcription factors $(O C T 3 / 4, S O X 2, C-M Y C$, and KLF4) in somatic cells [5]. Upon manipulation of their culture conditions in vitro or their transplantation into mice, iPSCs can be differentiated into numerous endodermal lineages, including hepatocytes [6]. iPSC-derived hepatocyte-like cells (HLCs) can be utilized in disease modeling, drug toxicity testing, and autologous cell therapies that would avoid immune rejection and enable the correction of genetic defects. In this review, we provide a summary of two effective routes including direct reprogramming and indirect reprogramming from somatic cells to hepatocytes and the general potential applications of the resulting hepatocytes. Through these approaches, we are advancing toward the goal of achieving a robust, mature source of clinically relevant lineages (Figure 1). 


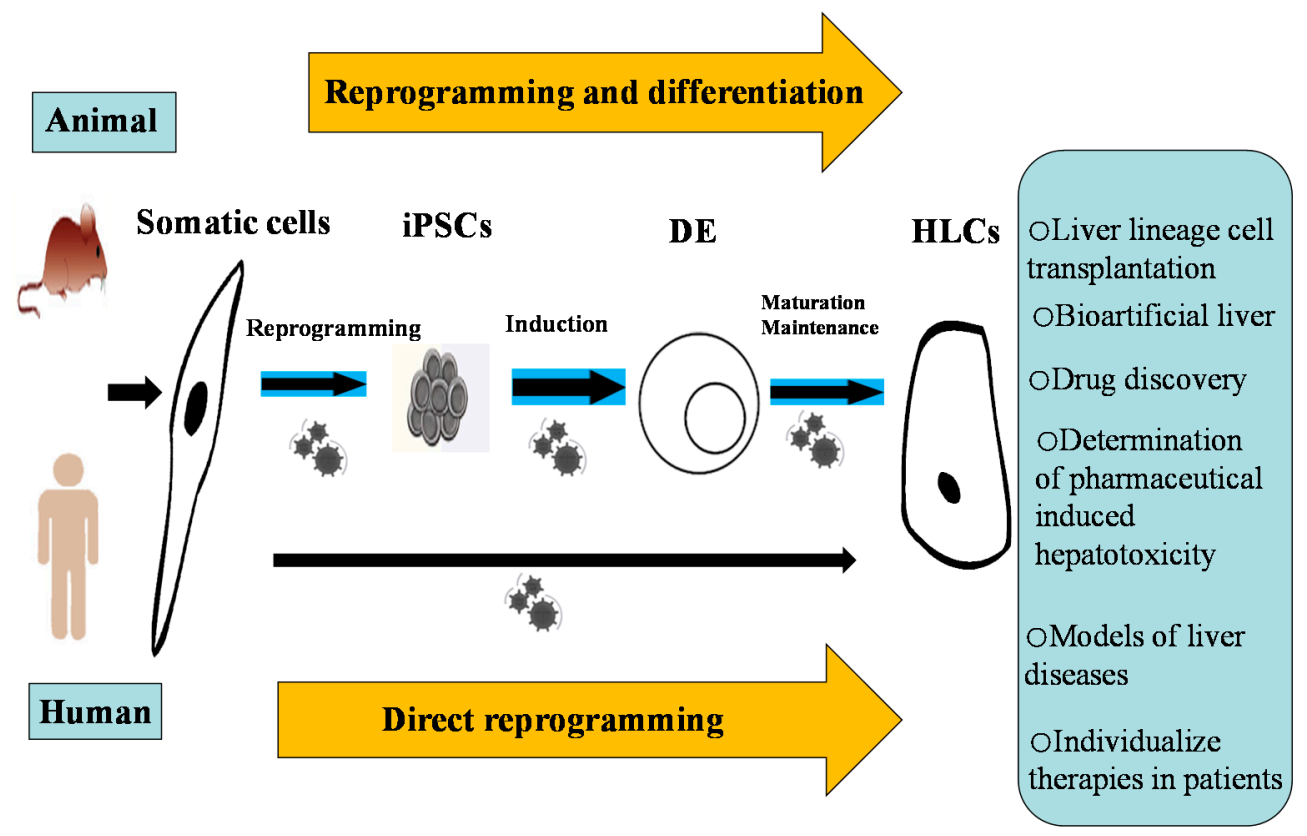

Figure 1. Promoting a unified field in induced pluripotent stem cell (iPSC)-derived HLCs and achieving a robust, mature source of clinically relevant lineages.

\section{Reprogramming Somatic Cells to Induced Pluripotent Stem Cell (iPSCs)}

Most studies have focused on generating iPSCs from somatic cells and have developed multiple routes to improve the efficiency of this process in different cell types. To reprogram efficiently and safely, several aspects must be considered. First, the reprogramming efficacy varies according to the cell type; thus, the choice of cell type may initially determine the transition efficiency; Second, reprogramming systems such as viral vectors, non-viral vectors, direct protein transduction and other new systems exhibit different efficiencies; Third, an optimized combination of reprogramming factors can enhance the reprogramming efficiency; Fourth, when culturing in vitro, the environment plays a crucial role in maintaining the function and potential usage of iPSCs; Last, genetic manipulation may result in mutations and abnormal karyotypes. By retroviral [7] or lentiviral [8] transduction of transcription factors, iPSCs were derived from somatic cells; however, this approach was associated with genome insertion and tumorigenicity risk. Human iPSC lines were later established from fibroblasts using adenoviral vectors, but extremely high viral titers had to be used in this reprogramming system [9]. Sendai virus, an RNA virus that does not integrate into the genome, is also capable of delivering reprogramming factors [10]; however, this system is difficult to manipulate and requires more than 15 passages to eliminate viral transgene expression. Non-integrating vectors including plasmids [11], episomal vectors [12], and minicircles [13] will not result in chromosomal abnormalities, but the efficiency is extremely low. An mRNA-based integration-free technique has been successfully used to generate iPSCs from adipose tissues and established personalized regenerative medicine within the clinic [14]. Moreover, iPSCs have been established by the direct delivery of recombinant reprogramming proteins [15] and small molecules [16]. Notably, a cocktail of SB431542, PD0325901, and thiazovivin has improved the reprogramming efficiency up to 200-fold [17]. Due to low transduction efficiency and unstable expression, the reprogramming efficiency of transgene-free 
methods is lower than with viral vectors. Therefore, developing efficient technologies that require less time is an urgent task.

Mouse and human cells can be reprogrammed by the ectopic expression of the transcription factors OCT3/4, SOX2, KLF4, and C-MYC [5]. OCT4 can be replaced by GATA3, GATA4, and GATA6, and SOX2 can be replaced by $S O X 1$ and $S O X 3$ [18]. BMI1 functionally replaced the three transcription factors $S O X 2, K L F 4$, and $C-M Y C$ and, along with OCT4, generated authentic iPSCs [19]. Samavarchi et al. [20] suggested that $N A N O G$ alone is sufficient to mediate the transition from pre-iPSCs to stably reprogrammed cells. Another study demonstrated that OCT4 is dispensable in the generation of porcine iPSCs [21]. Furthermore, over-expression or deletion of some transcription factors can affect reprogramming efficacy in addition to the classical transcription factors. For example, over-expression of MOF improves the reprogramming efficiency and facilitates iPSC formation [22]. PRMT5 over-expression in combination with OCT3/4, SOX2, KLF4, and C-MYC significantly increased the number of alkaline phosphatase-positive goat iPSCs compared to the four transcription factors alone [23]. SNAI1 and SNAI2 play opposite roles in NANOG-dependent reprogramming. Ectopic expression of $S N A I 1$ or depletion of $S N A I 2$ greatly facilitates $N A N O G$-driven reprogramming [24]. Successful reprogramming may depend on a stoichiometric balance of a combination of potential transcription factors.

ESC culture conditions for iPSCs may raise issues of microbial or viral transmission and immunogenicity. Thus, feeder-free culture systems to eliminate contamination are obligatory for scientists to develop clinical-grade iPSCs [25-27]. In addition to the culture system conditions, hypoxia will accelerate the reprogramming process [28]; therefore, the optimal $\mathrm{O}_{2}$ concentration should be determined [29]. In addition, a three-dimensional (3D) culture system provides a simple, efficient, and time-saving method for the provision of iPSCs at midi-scale [30]. In summary, combining all the optimized conditions such as the suitable cell source; excellent combination of reprogramming factors, non-integrated vectors or excisable vectors; and feeder-free culture systems or 3D culture systems, iPSCs can be safely generated and differentiated to other lineages for research or clinical applications.

\section{The Hepatic Differentiation Abilities of Different Sources Vary}

Many animal models (e.g., mouse [31] and porcine [32]) have been used to investigate the detailed mechanisms of iPSC hepatic differentiation. The reprogramming or differentiation effects of the tissue sources vary. For example, fetal hepatocytes can be reprogrammed much more efficiently than adult hepatocytes [33], and the hepatic differentiation efficiency of peripheral blood cell-derived iPSCs is better than that of adult dermal fibroblast-derived iPSCs [34]. When comparing peripheral blood- and dermal fibroblast-derived iPSCs from the same individuals, variations in hepatic differentiation were largely attributable to donor differences rather than to the original cell types [34]. Similar to other somatic cell lineages, hepatocyte-derived iPSCs were indistinguishable from ESCs with respect to colony morphology, growth properties, pluripotency-associated gene expression, surface marker expression, differentiation potential in embryoid body formation, and teratoma assays. In addition, the resulting iPSCs can directly differentiate into definitive endoderm, hepatic progenitors, and mature hepatocytes [35]. Hepatoblast-derived iPSCs were more efficient in directed differentiation toward the 
hepatic lineage than adult hepatocyte-derived iPSCs, mouse embryonic fibroblast-derived iPSCs, or mouse ESCs. These cells retained a transcriptional memory (seven up-regulated and 17 down-regulated genes) typical of the original cells; however, most of these differences, including a superior capacity for hepatic redifferentiation, were erased after continuous passaging [36]. Thus, the selection of somatic cell sources may result in different reprogramming efficiencies or differentiation efficiencies according to the various applications.

\section{The Characteristics of iPSC-Derived Hepatocyte-Like Cells (HLCs)}

iPSC-derived HLCs present an excellent alternative for addressing availability issues and provide key features of their native counterparts. Indeed, a set of criteria must be met before characterizing iPSC-derived cells as "hepatocyte-like" (Figure 2). Under electron microscopy, the appearance of polygonal cells containing multiple nuclei is suggestive of hepatocytes. Under transmission electron microscopy, glycogen granules within the cells, round nuclei with evenly distributed chromatin and Golgi complexes, well-developed bile canaliculi with apical microvilli, and tight junctions are characteristics of mature hepatocytes [37]. Each phase of differentiation is delineated by specific markers. At the molecular level, the intermediate phase of hepatogenesis is characterized by the expression of HNF1A, HNF4A, ALB, and CK18. HNF3B, AFP, and TTR are markers of primary hepatic differentiation, and $S O X 17, G S C$, and FOXA2 are well-known markers of definitive endoderm. Finally, mature hepatocytes are defined by the expression of TO, TAT, C/EBPA, CYPs, and $A G P R 1$ [38]. At the protein level, the production of albumin, urea, and alpha-1-antitrypsin and the induction of $P 450$ enzymatic activity following treatment with specific inducers and substrates to confirm phase I and II metabolic enzyme activity and their functional abilities are commonly tested in each phase of differentiation [39]. The stable expression and function of CYPs and transporters in iPSC-derived HLCs for at least one week allows long-term and extensive studies to be reproducibly performed [40]. These cells maintain the functional activity of many drug-metabolizing enzyme pathways and possess the capacity of active efflux of marker substrates into bile canalicular compartments. The uptake of low-density lipoprotein (LDL) [41] and the uptake and secretion of indocyanine green (ICG) [41] are specific to hepatocytes and, thus, are used to determine hepatocyte-specific function. Glycogen accumulation, as examined by Periodic acid-Schiff staining, indicates the generation of mature hepatocytes [41].

In addition to the above-mentioned "hepatocyte-like" characteristics, both iPSCs and ESCs were differentiated into liver-like tissue with similar mitochondrial development as measured by oxygen concentration and $\mathrm{pH}$ in the culture medium, corresponding to the oxygen consumption rate and extracellular acidification rate, respectively [42]. The iPSCs had low oxygen consumption and possessed small, immature mitochondria located around the nucleus. With maturation to HLCs, mitochondria exhibited elongated morphology, swollen cristae, and dense matrices as well as cytoplasmic migration, increased mitochondrial DNA transcription- and replication-related gene expression, and increased oxygen consumption [43]. Although efficient hepatic differentiation from mouse iPSCs was observed, mouse iPSCs showed relatively lower hepatic induction efficiency compared with mouse ESCs [44]. Notably, HLCs persistently express alpha fetoprotein and lack key mature hepatocyte functions, as reflected by the drastically reduced activity of many detoxification 
enzymes [45-47]. These subtle but important differences between HLCs and adult hepatocytes have limited the use of stem cells as a renewable source of functional hepatocytes. The seven major metabolic pathways (oxidation, dehydrogenation, ketone formation, and potential methylation in phase I and glucuronidation and conjugations of glucose and glutathione in phase II) of the drug bufuralol found in iPSC-derived HLCs resembled those of freshly isolated primary human hepatocytes [48]. However, an enrichment analysis of apoptotic pathways found that iPSC-derived HLCs are more similar to cryopreserved human hepatocytes than the hepatic cell lines HepaRG and Huh7 [49]. During the hepatic differentiation process in vitro, these markers and metabolic markers may help scientists to control the differentiation process and obtain particular target cells for applications in vitro or in vivo.
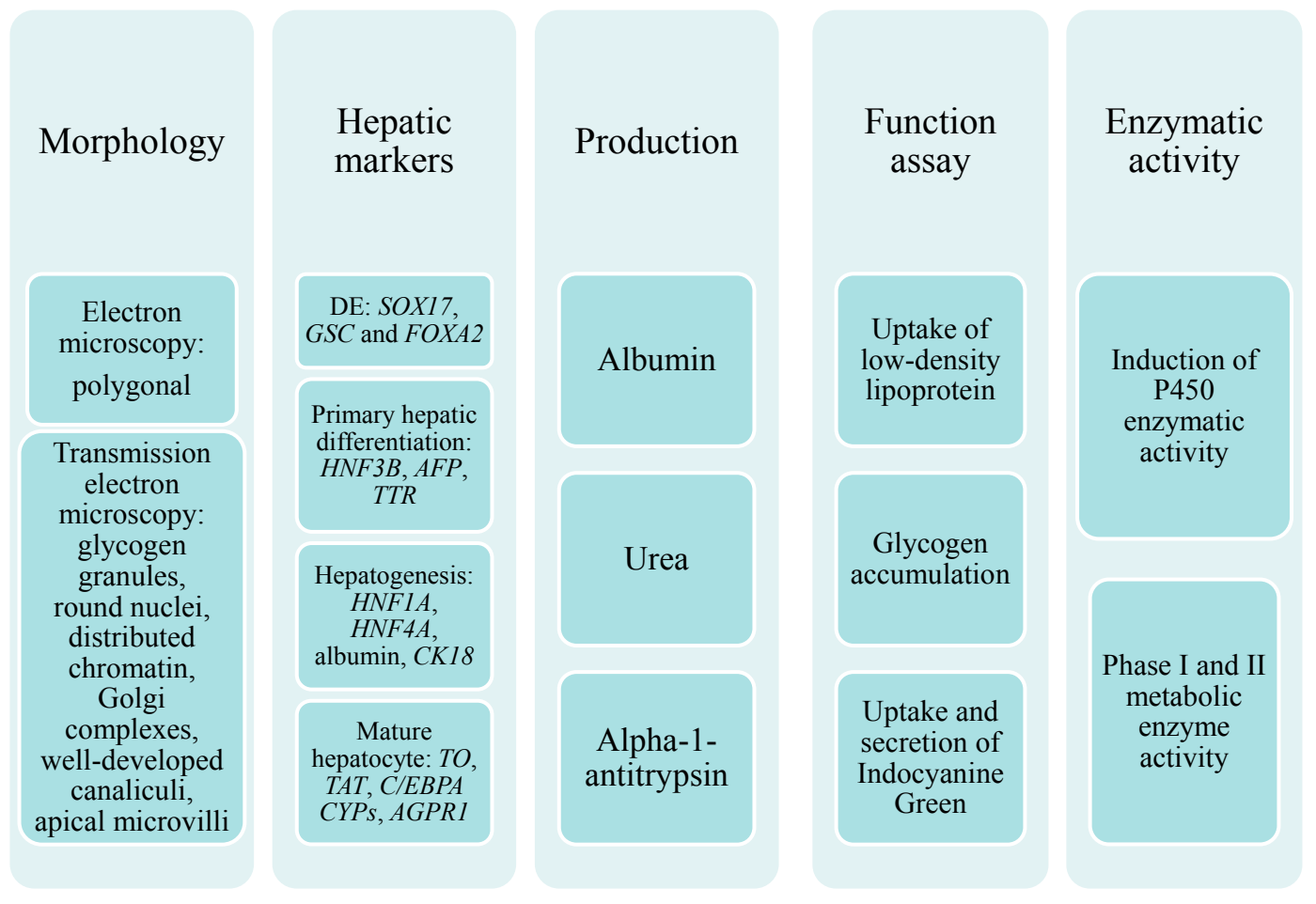

Figure 2. A set of criteria must be met before characterizing iPSC-derived cells as "hepatocyte-like".

\section{In Vitro Differentiation of iPSCs to HLCs}

By sequential stimulation with cytokines that are known to play a role in liver development, mouse iPSCs can be differentiated into two types of cells: one type with hepatoblast features and another type with hepatocyte characteristics [31]. Human liver development involves anterior endoderm differentiation, definitive endoderm formation, hepatoblast generation, and fetal or adult hepatocyte maturation [50]. Hepatic differentiation of iPSCs always occurs in a stepwise manner with high efficiency and reproducibility; however, simpler protocols of directed differentiation toward HLCs need to be developed for clinical usage [45,51-53] (Figure 3). Using a four-step differentiation protocol, human iPSCs were differentiated to definitive endoderm in response to activin $A$ and exhibited hepatic specification in response to $B M P 4 / F G F 2$, hepatoblast formation in response to $H G F$, and hepatocyte-like differentiation in response to oncostatin $M$ [45]. By following a three-step differentiation protocol using activin $A, b F G F, B M P 4$, and oncostatin $M$, the resulting iPSC-derived 
HLCs could represent a valuable hepatocyte source [51]. The hepatic differentiation efficiency of another two-step protocol with high doses of activin $A$ and $H G F$ was comparable to the four-step induction protocol [52]. Exposure to FOXA2, GATA4, HEX, C/EBPA, dexamethasone and ITS supplementation potentially serves as a single-step inducer for the differentiation of iPSCs into hepatic progenitor-like cells within eight days [53].

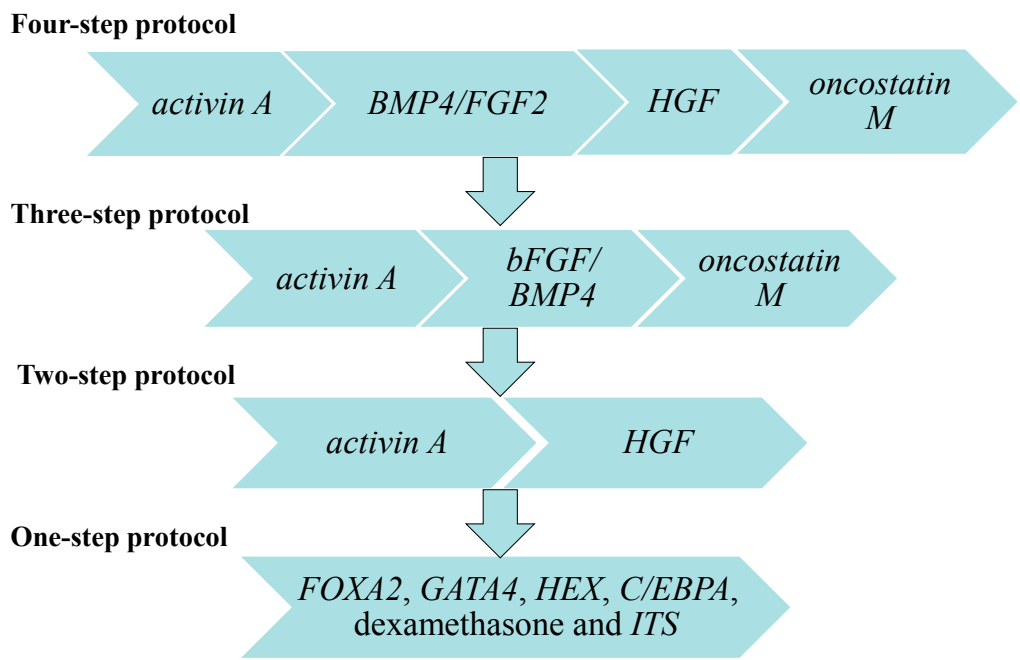

Figure 3. General protocols for in vitro hepatic differentiation of iPSCs.

\subsection{Differentiation to Immature HLCs}

The differentiation propensity toward definitive endoderm was affected by donor origin but not by reprogramming methods or cell origin [54]. Successful promotion of iPSCs to a definitive endoderm fate at high efficiency and low cell density during induction is vital for the differentiation efficiency [55]. The utilization of an embryoid body step in cultures typically introduced an unpredictable degree of variability between hepatic differentiation attempts. To address this problem, monolayer culture, hepatocyte reporter construct, and specific cell surface marker selection [56] are useful protocols for distinguishing the purified populations for functional testing in a variety of hepatocyte transplantation assays. In the middle stage of iPSC hepatic differentiation, Ki67 immunostaining showed an abundance of proliferating hepatic progenitor cells [57]. Unfortunately, the cells in the middle stage were unable to be re-plated and recycled in vitro [37]; they could only be differentiated to terminal HLCs for numerous applications.

Currently, many cytokines and small molecules (signaling pathway regulators or epigenetic regulators) are able to influence the hepatic differentiation efficacy. PI3-kinase blocks the inductive effect of activin/nodal on definitive endoderm differentiation by controlling the activity of WNT signaling, and inhibition of this pathway significantly improves the differentiation of iPSCs to definitive endoderm [58]. The early differentiation to meso-endoderm and the subsequent distinction of mesenchyme and endoderm is driven primarily by the nodal, $B M P$, and activin signaling pathways [59]. A combination of human activin $A$ with B27 minus insulin can efficiently differentiate human iPSCs into definitive endoderm at a rate of above 90\% [60]. Under feeder- and serum-free conditions, overtreatment with CHIR99021 converted the cells into mesoderm cells rather than endoderm [55]. Human ESC-derived fibroblast-like cell-secreted factors act in concert with the 
central region of ESCs and are able to induce robust hepatic endoderm differentiation on iPSCs [61]. In addition, triiodothyronine induces Krüppel-like factor 9 in ESCs and iPSCs, and this effect persists during differentiation to definitive endoderm and hepatocytes [62]. With the help of poly( $\varepsilon$-caprolactone) nanofibrous scaffolds, definitive endoderm was able to be generated from iPSCs within a six-day induction period [63].

Initiated by hepatocyte differentiation-initiating medium, iPSCs were converted to hepatoblast-like cells, but a small number of immature hepatocytes was obtained [64]. To improve efficacy, a $H E X$-expressing adenovirus vector was used under serum/feeder cell-free chemically defined conditions, and iPSCs were efficiently induced to hepatoblasts [65]. The resulting cells expressed alpha fetoprotein at day nine and expressed albumin at day 12. Thus, developing new factors or clarifying the mechanism underlying the process is extremely helpful for the generation of functional HLCs.

\subsection{Maturation of iPSC-Derived Hepatic Lineage Cells}

As with immature HLC differentiation, the developmental pathways that control hepatocyte maturation from the fetal to the adult state are poorly understood; this issue has hampered the clinical usage of these cells. By culturing embryoid bodies in specific cytokine cocktails or on different extracellular matrices in an effort to mimic signals observed during embryonic liver development, the efficiency of iPSC-derived HLC generation can be improved [66].

The introduction of human HNF6 markedly increased the expression of CYP3A4 and other CYP genes in iPSC-derived HLCs as well as in HepG2 cells and hepatocytes, but the hepatocyte-specific gene expression levels in iPSC-derived HLCs were very low compared with those in HepG2 cells and hepatocytes [67]. FOXA2 and HNF1A promoted efficient hepatic differentiation from human ESCs and iPSCs, and the expression profiles of hepatic marker genes were comparable to those of primary human hepatocytes [68]. Adenovirus vector-mediated over-expression of $H N F 4 A$ in induced hepatoblasts led to the up-regulation of epithelial and mature hepatic markers and promoted hepatic maturation by activating mesenchymal-to-epithelial transition [69]. When knocking in a monomeric Kusabira-Orange ( $\mathrm{mKO1}$ ) cassette in the albumin gene for human ESCs and iPSCs using helper-dependent adenovirus, the hepatic marker genes, drug metabolism genes, and many aspects of liver function were highly enriched in the $A L B / m K O 1$ (Hi) population [70]. Efficiency can also be improved without exogenous factors. For example, with the addition of human serum from patients undergoing hepatectomy [71], differentiated cells expressed hepatic marker genes and drug-metabolizing enzymes and exhibited drug-metabolizing enzyme activities.

Shan et al. [72] developed a high-throughput screening platform for primary human hepatocytes to identify two different classes of small molecules that can be used to generate renewable sources of functional human hepatocytes. Valproic acid inhibited histone deacetylase activity during the differentiation of human iPSCs, and the HLCs expressed hepatic marker genes and drug-metabolizing enzymes and exhibited drug-metabolizing enzyme activities after 25 days of hepatic differentiation [73]. A similar phenomenon was observed in modified L-15 medium containing galactose, phenylalanine, and ornitine but deprived of glucose, tyrosine, arginine, and pyruvic acid [74]. Vitamin K2 and lithocholic acid activated pregnane $\mathrm{X}$ receptor, while albumin and apolipoprotein B100 were at levels equivalent to primary human hepatocytes [75]. Intriguingly, small molecules (CHIR99021, BIO, DMSO, 
dexamethasone, and dihexa) in a defined minimum medium without any of the exogenous growth factors necessary for hepatic specification promoted approximately $90 \%$ of iPSCs to HLCs [76,77]. Paracrine signals produced by the different subpopulations of liver-derived mesenchymal stem cells purified with immunoselection technologies have been identified and shown to induce the differentiation of human hepatic stem cells into fully mature and functional parenchymal cells [78]. Signaling pathways including BMP4, FGF2, and FGF4 can induce differentiation to hepatoblasts; after liver bud formation and expansion, $H G F$ and oncostatin signals stimulate the hepatoblasts to differentiate into hepatocytes [59]. In addition, Wnt/ $\beta$-catenin signaling can induce the fate change of endodermal cells into a liver fate in a cell-autonomous manner [79].

\subsection{Three-Dimensional (3D) Culture for Hepatic Differentiation}

Under monolayer culture conditions, hepatocytes lose their liver-specific functions within a few days, leading to an extraordinary decrease in functional HLCs. iPSCs can be aggregated in suspension or on specialized plates, and this characteristic results in the formation of 3D structures that may serve to replicate some of the cell-cell and cell-matrix signals similar to hepatic development in vivo (Table 1) [80].

Table 1. iPSC hepatic differentiation under special 2D or 3D environments.

\begin{tabular}{|c|c|c|c|c|c|}
\hline Species & Cell Type & Target Cell & 2D/3D Culture & Efficiency & Reference \\
\hline Human & iPSCs & $\begin{array}{l}\text { Definitive } \\
\text { endoderm }\end{array}$ & $\begin{array}{l}\text { Poly( } \varepsilon \text {-caprolactone) nanofibrous } \\
\text { scaffold }\end{array}$ & $\begin{array}{c}\text { Reduced cell stress, rapid cell adaption, } \\
\text { and high viability, growth, and } \\
\text { differentiation }\end{array}$ & {$[63]$} \\
\hline Human & iPSCs & $\begin{array}{l}\text { Definitive } \\
\text { endoderm }\end{array}$ & $\begin{array}{l}\text { CHIR99021/Wnt3A ligand under } \\
\text { feeder- and serum-free conditions }\end{array}$ & Easier handling and higher efficiency & {$[55]$} \\
\hline Human & iPSCs & Hepatoblasts & $\begin{array}{c}\text { Serum/feeder cell-free chemically } \\
\text { defined conditions }\end{array}$ & $\begin{array}{c}\text { Faster transition, more functional and } \\
\text { higher efficiency }\end{array}$ & {$[65]$} \\
\hline Mouse & iPSCs & HLCs & $\begin{array}{l}\text { 3D micro-cavitary } \\
\text { hydrogel system }\end{array}$ & $\begin{array}{c}\text { Nutrient exchange enhancement, } \\
\text { greater living space, faster transition, } \\
\text { and higher efficiency }\end{array}$ & {$[81]$} \\
\hline Human & iPSCs & HLCs & Nanofiber scaffolds & More functional and higher efficiency & {$[82]$} \\
\hline Human & iPSCs & HLCs & 3D micropattern plate & $\begin{array}{l}\text { More functional, higher efficiency, } \\
\text { large number of HLCs for industrial } \\
\text { and clinical applications }\end{array}$ & {$[83]$} \\
\hline Human & iPSCs & HLCs & $\begin{array}{c}\text { Scalable stirred-suspension } \\
\text { bioreactor } \\
\end{array}$ & $\begin{array}{l}\text { Multiple features of primary hepatocytes } \\
\text { and persistent function in vivo }\end{array}$ & {$[84]$} \\
\hline Mouse & iPSCs & HLCs & $\begin{array}{l}\text { Combination of a bioreactor } \\
\text { module with a } 0.2 \mu \mathrm{m} \\
\text { pore membrane }\end{array}$ & $\begin{array}{l}\text { Act as a promising option for } \\
\text { bioartificial liver systems }\end{array}$ & {$[85]$} \\
\hline Human & iPSCs & HLCs & $\begin{array}{l}\text { 3D collagen matrices compatible } \\
\text { with high-throughput screening }\end{array}$ & $\begin{array}{l}\text { Promote functional maturation and } \\
\text { improve functional longevity to over } \\
75 \text { days }\end{array}$ & {$[86]$} \\
\hline Human & iPSCs & HLCs & $\begin{array}{l}\text { A micro-patterned } \\
\text { co-culture platform }\end{array}$ & $\begin{array}{c}\text { Promote functional maturation and } \\
\text { improve functional longevity to over } \\
\text { four weeks }\end{array}$ & {$[87]$} \\
\hline
\end{tabular}


Table 1. Cont.

\begin{tabular}{cccccc}
\hline Species & Cell Type & Target Cell & 2D/3D Culture & Efficiency & Reference \\
\hline \multirow{2}{*}{ Human } & $\begin{array}{c}\text { iPSC derived- } \\
\text { hepatoblasts }\end{array}$ & HLCs & $\begin{array}{c}\text { Combination of 3D cell } \\
\text { aggregation and } \\
\text { cAMP signaling }\end{array}$ & $\begin{array}{c}\text { Comparable function to primary } \\
\text { human hepatocytes, more } \\
\text { simple and reproducible }\end{array}$ & [88] \\
\hline \multirow{2}{*}{ Human } & $\begin{array}{c}\text { iPSC derived- } \\
\text { hepatoblasts }\end{array}$ & HLCs & Human laminin 111-coated dish & $\begin{array}{c}\text { Longevity of more than } \\
\text { 3 months }\end{array}$ \\
\hline \multirow{2}{*}{ Human } & iPSCs & Liver bud & $\begin{array}{c}\text { Coculture with endothelial cells } \\
\text { and mesenchymal stem cells, } \\
\text { and then mixed cells are plated } \\
\text { onto a presolidified matrix }\end{array}$ & $\begin{array}{c}\text { Fast formation of liver bud and } \\
\text { act as a functional liver } \\
\text { in vivo }\end{array}$ & [90] \\
\hline
\end{tabular}

Three-dimensional collagen matrices compatible with high-throughput screening [86], a micro-cavitary hydrogel platform system [81], and a micro-patterned co-culture platform [87] significantly increased the functional maturation of iPSC-derived HLCs toward an adult phenotype compared to conventional $2 \mathrm{D}$ systems. The combination of 3D cell aggregation and cAMP signaling enhanced the maturation of human iPSC-derived hepatoblasts to an HLC population that displays expression profiles and metabolic enzyme levels comparable to those of primary human hepatocytes [88]. Furthermore, by culturing on a human laminin 111-coated dish, human iPSC-derived hepatoblast-like cells were maintained for more than three months and had the ability to differentiate into both HLCs and cholangiocyte-like cells [89]. When iPSC-derived specified hepatic cells were dissociated and suspended with endothelial cells and mesenchymal stem cells and then plated onto a presolidified matrix [90], the immature endodermal cells self-organized into 3D liver buds by recapitulating the organogenetic interactions between endothelial and mesenchymal cells. The formation of functional vasculatures stimulated the maturation of iPSC liver buds into tissue resembling the adult liver [91].

\section{Direct Reprogramming as an Alternative}

Lineage reprogramming, which can be defined as the direct induction of functional cell types from one lineage to another lineage without passing through an intermediate pluripotent stage [92], avoids the potential problems associated with the time-consuming and labor-intensive generation of iPSC lines. Interestingly, the directly reprogrammed functional hepatocytes possess high proliferative potential, whereas such proliferative potential has not been reported for HLCs derived from iPSCs.

Zhu et al. did not generate iPSCs but instead cut short the reprogramming to pluripotency to generate an induced multipotent progenitor cell state. Subsequently, the HLCs could be efficiently differentiated [93]. By over-expressing the hepatic fate conversion factors $H N F 1 A, H N F 4 A$, and HNF6 along with the maturation factors $A T F 5, P R O X 1$, and $C / E B P A$, directly reprogrammed HLCs express a spectrum of phase I and II drug-metabolizing enzymes and phase III drug transporters. Importantly, the metabolic activities are comparable between reprogrammed HLCs and freshly isolated primary human hepatocytes [94]. In another study, over-expression of GATA4, HNF1A, and FOXA3 along with p19ARF inactivation enabled mouse fibroblasts to become HLCs [95] that exhibited typical epithelial morphology, expressed hepatic genes, and acquired hepatocyte functions. A combination of $H N F 4 A$ with FOXA1, FOXA2, or FOXA3 was used to transfect and reprogram adult mouse fibroblasts to 
HLCs, and the efficiency was approximately one in 1000 of the initially transfected embryonic fibroblasts [96]. With repeated transfection of synthetic modified mRNAs (HNF1A plus any two of the factors $F O X A 1, F O X A 3$, or $H N F 4 A$ ), the directly reprogrammed cells also exhibited hepatic morphology and protein expression [97]. In addition to fibroblasts, spermatogonial stem cells (SSCs) can trans-differentiate to hepatic stem-like cells that are capable of differentiating into cells with the morphological, phenotypic, and functional characteristics of mature hepatocytes via activation of the ERK1/2 and SMAD2/3 signaling pathways and inactivation of cyclin A, cyclin B, and cyclin E [98]. Considering the omission of a pluripotent state and hepatic function comparable to primary hepatocytes, direct reprogramming to HLCs may act as a promising route to produce a large number of HLCs without the laborious generation of iPSCs for clinical usage.

\section{In Vivo Hepatic Differentiation of iPSCs}

Transplanted iPSCs engrafted, integrated, and proliferated in the liver and the surviving stem cells secreted albumin, indicating that iPSCs can differentiate to HLCs and function in vivo [48]. Preliminary transplantation experiments not only confirmed engraftment but also showed teratoma formation, which needs to be excluded using more stringent purification strategies [99]. Intravenous transplantation of iPSCs effectively reduced the hepatic necrotic area, improved liver function and motor activity, and rescued lethal acute liver failure [100]. Human iPSCs of distinct origins, regardless of their parental epigenetic memory, can efficiently differentiate along the hepatic lineage to regenerate mouse liver [101,102]. When iPSC-derived HLCs at different stages were transplanted, 15- and 20-day hepatic differentiated cells engrafted into the livers and further acquired hepatocyte morphology. In contrast, five- and 10-day differentiated cells were able to engraft but did not generate HLCs in vivo [103]. To enhance the repopulation efficacy, the apoptosis of human iPSC-derived HLCs during the transplantation process was inhibited by transducing with an adenovirus vector expressing FNK [104]. To clarify the potential therapeutic effects in vivo, scientists set out to compare the resulting functional HLCs from hepatic differentiation in vivo and in vitro. Transplantation of iPSCs performed better than iPSC-derived HLCs in reducing ALT and AST levels in the serum of patients and the liver necrosis areas [105], and the hepatoprotective effect appeared to originate from the higher antioxidant activity [106]. Both iPSCs and iPSC-derived HLCs potentially suppressed ROS production and activated antioxidant enzymes in injured livers to repair the injured liver [107].

In a $3 \mathrm{D}$ environment, iPSC-derived HLCs can efficiently rescue impaired liver function. When suspended with endothelial cells and mesenchymal stem cells and plated onto a pre-solidified matrix, iPSC-derived HLCs formed a 3D spherical tissue mass termed a liver bud and performed multiple hepatic functions in a chronological manner in vivo after transplantation [90]. Furthermore, mesenteric transplantation of liver buds rescued the drug-induced lethal liver failure model and performed liver-specific functions such as protein production and human-specific drug metabolism without recipient liver replacement [91]. With the delivery of miR122 and carboxymethyl-hexanoyl chitosan, the period of iPSC hepatic differentiation was shortened, and the resulting HLCs exhibited promising hepatoprotective efficacy in vivo [108].

Since various laboratories began to directly reprogram somatic cells into HLCs, they also detected the directly reprogrammed HLCs in vivo to simultaneously evaluate the application prospects. 
After transplantation into an immune-deficient mouse model of human liver failure, the directly reprogrammed HLCs proliferated extensively and acquired levels of hepatocyte function similar to those of primary hepatocytes. Unlike the differentiated HLCs, these reprogrammed HLCs did not form tumors most likely because they never entered a pluripotent state [93]. In particular, the directly reprogrammed HLCs were able to repopulate the livers of fumarylacetoacetate hydrolase-deficient mice and were sufficient to restore liver function and rescue $40 \%$ of recipient mice from death $[95,96]$.

\section{The Potential Applications of iPSC-Derived HLCs}

Transplantation of liver lineage cells or tissue-engineered liver tissue analogs [107] and extracorporeal bioartificial liver devices [109] are two promising applications for HLC therapies. Nevertheless, these two applications are inhibited by oncogenesis and by cell scarcity. Evidence has shown that iPSCs frequently acquire aneuploidies and recurrent abnormalities [110]. These cells may retain the inactive $\mathrm{X}$ chromosome from the somatic cell source [111] or reactivate the inactive $\mathrm{X}$ and display two active $\mathrm{X}$ chromosomes [112]. Long-term culture has also been associated with malignant embryonic carcinoma cells [113]. Abnormal epigenetic modifications can ultimately affect the pluripotency of iPSCs; the disrupted methylation could not be recovered by optimizing culture conditions or by subcloning iPSCs. In addition, reactivation of $C-M Y C$ might result in tumor formation, but the absence of $C-M Y C$ drastically reduced the reprogramming efficiency and resulted in subtle abnormal epigenetic modifications [114]. Although the genomic integrity of iPSCs has limited their clinical applications, numerous reprogramming strategies were developed to minimize the disturbance of the iPSC genome. While aneuploidy is commonly associated with cell transformation, iPSCs that harbor abnormal chromosomal content retain the capacity to generate HLCs with high efficiency [115].

Currently, HLCs are extensively used as platforms for drug discovery [116] or for the determination of pharmaceutical-induced hepatotoxicity [117], as models of liver diseases [118], and as individual therapies in patients [119]. To determine individual drug effects on disease-specific iPSC-derived functional cell types, the disease phenotypes need to be recapitulated consistently and uniformly. Disease modeling conditions must be further developed and differentiation conditions must be further optimized for more accurate disease modeling and drug screening. iPSCs were generated from a cohort carrying mutations (PiZZ) in the gene responsible for $\alpha-1$ antitrypsin $(A A T)$ deficiency. The expression of 135 genes distinguished PiZZ iPSC-derived HLCs, which displayed intracellular accumulation of mutant $A A T$ protein, resulting in increased autophagic flux but adverse responses to known hepatotoxic drugs [120]. Through a blind large-scale drug screening, five clinical drugs were identified that reduced $A A T$ accumulation in patient iPSC-derived HLCs. In addition, using the recently developed transcription activator-like effector nuclease technology, Choi et al. achieved a high gene-targeting efficiency in $A A T$-deficient patient iPSCs, with 25\%-33\% of the clones demonstrating simultaneous targeting at both diseased alleles [121]. HLCs obtained from patient-derived iPSCs could also be used as a platform for individualize therapies without immune suppression. Meanwhile, many congenital liver diseases benefit from these reprogrammed cell-based therapies. HLCs were found to recapitulate key pathological features of the diseases affecting the patients from which they were derived [119]. Combined with directed cell differentiation strategies, Wilson's disease-derived iPSCs were successfully differentiated into HLCs, neural stem cells, and neurons, accompanied by the expression 
of the mutant $A T P 7 B$ gene in all differentiated cells [122]. When combined with the capacity to engineer genetic changes in established iPSCs [123], patient-specific iPSCs and HLCs can be utilized to study genetic variants identified in Genome-wide association studies (GWAS) studies as well as a host of other monogenic alterations to assay their impact on hepatocyte differentiation, phenotype, and function [124], thus facilitating the in vitro tmodeling of rare diseases. In addition, the patient-derived cells will also facilitate the direct investigation of hepatitis B and $\mathrm{C}$ viruses in human hepatocytes and the determination of the genetic influence on the susceptibility of hepatocytes to these viruses [125]. After improving the differentiation efficacy and eliminating genomic disturbance, these somatic cell-derived HLCs may one day enable personalized medicine.

\section{Conclusions}

In summary, recent technical advances in reprogramming somatic cells to iPSCs with different reprogramming systems and alternative combinations of transcription factors will lead to numerous pluripotent stem cells without gene modifications. In addition, feeder-free culture systems and 3D culture systems play extremely important roles in the generation of clinical-grade pluripotent cells. However, the incomplete hepatic differentiation state of iPSCs likely results from our poor understanding of the mechanisms underlying the developmental shift from fetal to adult liver. Thus, after clarifying the characteristics of different hepatic differentiation stages, the handling of this process will be easier and more efficient. The differentiation protocols combined with the development of complex culture systems will significantly improve the quality and spectrum of iPSC-derived hepatocyte-like cell types. In contrast, the direct reprogramming of HLCs that bypass the pluripotent state could occur efficiently in vitro and in vivo. As these novel technologies become rapidly available in the reprogramming or differentiation field, they may enable studies at the deepest molecular level, linking genetics, epigenetics, and phenotypes in the context of complex liver disorders. Although iPSCs are accompanied by abnormal chromosomes, these pluripotent cells remain able to differentiate to mature HLCs. It is likely that the generation of safe and effective HLCs for cell therapy as well as disease modeling and drug screening will be possible in the near future.

\section{Acknowledgments}

This work was supported by the National Natural Science Foundation of China (No. 81471794), the Chinese High Tech Research \& Development (863) Program (No. SS2013AA020102) and the National Science and Technology Major Project (No. 2012ZX10002004).

\section{Author Contributions}

Chenxia $\mathrm{Hu}$ contributed to literature review, concept, and writing of this manuscript. Lanjuan Li contributed to concept of this manuscript.

\section{Conflicts of Interest}

The authors declare no conflict of interest. 


\section{Abbreviations}

ESCs: embryonic stem cells; iPSCs: induced pluripotent stem cells; HLCs: hepatocyte-like cells; LDL: low-density lipoprotein; ICG: indocyanine green; mKO1: monomeric Kusabira-Orange; 3D: three-dimensional; SSCs: spermatogonial stem cells; AAT: alpha-1 antitrypsin.

\section{References}

1. Kmiec, Z. Cooperation of liver cells in health and disease. Adv. Anat. Embryol. Cell Biol. 2001, $161,1-151$.

2. Gonzalez, S.A.; Keeffe, E.B. Chronic viral hepatitis: Epidemiology, molecular biology, and antiviral therapy. Front. Biosci. 2011, 16, 225-250.

3. Dhawan, A.; Strom, S.C.; Sokal, E.; Fox, I.J. Human hepatocyte transplantation. Methods Mol. Biol. 2010, 640, 525-534.

4. Ito, M.; Nagata, H.; Miyakawa, S.; Fox, I.J. Review of hepatocyte transplantation. J. Hepatobiliary Pancreat. Surg. 2009, 16, 97-100.

5. Takahashi, K.; Yamanaka, S. Induction of pluripotent stem cells from mouse embryonic and adult fibroblast cultures by defined factors. Cell 2006, 126, 663-676.

6. Cheng, X.; Ying, L.; Galvao, A.M.; Mills, J.A.; Lin, H.C.; Kotton, D.N.; Shen, S.S.; Nostro, M.C.; Lu, L.; Choi, J.K.; et al. Self-renewing endodermal progenitor lines generated from human pluripotent stem cells. Cell Stem Cell 2012, 10, 371-384.

7. Afanassieff, M.; Tapponnier, Y.; Savatier, P. Generation of induced pluripotent stem cells in rabbits. Methods Mol. Biol. 2014, doi:10.1007/7651_2014_140.

8. Varga, E.; Nemes, C.; Davis, R.P.; Ujhelly, O.; Klincumhom, N.; Polgar, Z.; Muenthaisong, S.; Pirity, M.K.; Dinnyes, A. Generation of transgene-free mouse induced pluripotent stem cells using an excisable lentiviral system. Exp. Cell Res. 2014, 322, 335-344.

9. Zhou, W.; Freed, C.R. Adenoviral gene delivery can reprogram human fibroblasts to induced pluripotent stem cells. Stem Cells 2009, 27, 2667-2674.

10. Nishimura, K.; Sano, M.; Ohtaka, M.; Furuta, B.; Umemura, Y.; Nakajima, Y.; Ikehara, Y.; Kobayashi, T.; Segawa, H.; Takayasu, S.; et al. Development of defective and persistent Sendai virus vector: A unique gene delivery/expression system ideal for cell reprogramming. J. Biol. Chem. 2011, 286, 4760-4771.

11. Qu, X.; Liu, T.; Song, K.; Li, X.; Ge, D. Induced pluripotent stem cells generated from human adipose-derived stem cells using a non-viral polycistronic plasmid in feeder-free conditions. PLoS ONE 2012, 7, e48161.

12. Piao, Y.; Hung, S.S.; Lim, S.Y.; Wong, R.C.; Ko, M.S. Efficient generation of integration-free human induced pluripotent stem cells from keratinocytes by simple transfection of episomal vectors. Stem Cells Transl. Med. 2014, 3, 787-791.

13. Jia, F.; Wilson, K.D.; Sun, N.; Gupta, D.M.; Huang, M.; Panetta, N.J.; Chen, Z.Y.; Robbins, R.C.; Li, Z.; Kay, M.A.; et al. A nonviral minicircle vector for deriving human iPS cells. Nat. Methods 2010, 7, 197-199. 
14. Heng, B.C.; Heinimann, K.; Miny, P.; Iezzi, G.; Glatz, K.; Scherberich, A.; Zulewski, H.; Fussenegger, M. mRNA transfection-based, feeder-free, induced pluripotent stem cells derived from adipose tissue of a 50-year-old patient. Metab. Eng. 2013, 18, 9-24.

15. Zhou, H.; Wu, S.; Joo, J.Y.; Zhu, S.; Han, D.W.; Lin, T.; Trauger, S.; Bien, G.; Yao, S.; Zhu, Y.; et al. Generation of induced pluripotent stem cells using recombinant proteins. Cell Stem Cell 2009, 4, 381-384.

16. Yuan, X.; Wan, H.; Zhao, X.; Zhu, S.; Zhou, Q.; Ding, S. Brief report: Combined chemical treatment enables Oct4-induced reprogramming from mouse embryonic fibroblasts. Stem Cells 2011, 29, 549-553.

17. Lin, T.; Ambasudhan, R.; Yuan, X.; Li, W.; Hilcove, S.; Abujarour, R.; Lin, X.; Hahm, H.S.; Hao, E.; Hayek, A.; et al. A chemical platform for improved induction of human iPSCs. Nat. Methods 2009, 6, 805-808.

18. Montserrat, N.; Nivet, E.; Sancho-Martinez, I.; Hishida, T.; Kumar, S.; Miquel, L.; Cortina, C.; Hishida, Y.; Xia, Y.; Esteban, C.R.; et al. Reprogramming of human fibroblasts to pluripotency with lineage specifiers. Cell Stem Cell 2013, 13, 341-350.

19. Moon, J.H.; Heo, J.S.; Kim, J.S.; Jun, E.K.; Lee, J.H.; Kim, A.; Kim, J.; Whang, K.Y.; Kang, Y.K.; Yeo, S.; et al. Reprogramming fibroblasts into induced pluripotent stem cells with Bmil. Cell Res. 2011, 21, 1305-1315.

20. Samavarchi-Tehrani, P.; Golipour, A.; David, L.; Sung, H.K.; Beyer, T.A.; Datti, A.; Woltjen, K.; Nagy, A.; Wrana, J.L. Functional genomics reveals a BMP-driven mesenchymal-to-epithelial transition in the initiation of somatic cell reprogramming. Cell Stem Cell 2010, 7, 64-77.

21. Montserrat, N.; de Onate, L.; Garreta, E.; Gonzalez, F.; Adamo, A.; Eguizabal, C.; Hafner, S.; Vassena, R.; Izpisua Belmonte, J.C. Generation of feeder-free pig induced pluripotent stem cells without Pou5f1. Cell Transpl. 2012, 21, 815-825.

22. Mu, X.; Yan, S.; Fu, C.; Wei, A. The histone acetyltransferase MOF promotes induces generation of pluripotent stem cells. Cell. Reprogram. 2015, 17, 259-267.

23. Chu, Z.; Niu, B.; Zhu, H.; He, X.; Bai, C.; Li, G.; Hua, J. PRMT5 enhances generation of induced pluripotent stem cells from dairy goat embryonic fibroblasts via down-regulation of p53. Cell Prolif. 2015, 48, 29-38.

24. Gingold, J.A.; Fidalgo, M.; Guallar, D.; Lau, Z.; Sun, Z.; Zhou, H.; Faiola, F.; Huang, X.; Lee, D.F.; Waghray, A.; et al. A genome-wide RNAi screen identifies opposing functions of Snail and Snai2 on the Nanog dependency in reprogramming. Mol. Cell 2014, 56, 140-152.

25. Ghodsizadeh, A.; Taei, A.; Totonchi, M.; Seifinejad, A.; Gourabi, H.; Pournasr, B.; Aghdami, N.; Malekzadeh, R.; Almadani, N.; Salekdeh, G.H.; et al. Generation of liver disease-specific induced pluripotent stem cells along with efficient differentiation to functional hepatocyte-like cells. Stem Cell Rev. 2010, 6, 622-632.

26. Chichagova, V.; Sanchez-Vera, I.; Armstrong, L.; Steel, D.; Lako, M. Generation of human induced pluripotent stem cells using RNA-based Sendai virus system and pluripotency validation of the resulting cell population. Methods Mol. Biol. 2015, doi:10.1007/7651_2015_205.

27. Chen, J.; Liu, J.; Han, Q.; Qin, D.; Xu, J.; Chen, Y.; Yang, J.; Song, H.; Yang, D.; Peng, M.; et al. Toward an optimized culture medium for the generation of mouse induced pluripotent stem cells. J. Biol. Chem. 2010, 285, 31066-31072. 
28. Shimada, H.; Hashimoto, Y.; Nakada, A.; Shigeno, K.; Nakamura, T. Accelerated generation of human induced pluripotent stem cells with retroviral transduction and chemical inhibitors under physiological hypoxia. Biochem. Biophys. Res. Commun. 2012, 417, 659-664.

29. Yoshida, Y.; Takahashi, K.; Okita, K.; Ichisaka, T.; Yamanaka, S. Hypoxia enhances the generation of induced pluripotent stem cells. Cell Stem Cell 2009, 5, 237-241.

30. Elanzew, A.; Sommer, A.; Pusch-Klein, A.; Brustle, O.; Haupt, S. A reproducible and versatile system for the dynamic expansion of human pluripotent stem cells in suspension. Biotechnol. J. 2015, doi:10.1002/biot.201400757.

31. Sancho-Bru, P.; Roelandt, P.; Narain, N.; Pauwelyn, K.; Notelaers, T.; Shimizu, T.; Ott, M.; Verfaillie, C. Directed differentiation of murine-induced pluripotent stem cells to functional hepatocyte-like cells. J. Hepatol. 2011, 54, 98-107.

32. Ao, Y.; Mich-Basso, J.D.; Lin, B.; Yang, L. High efficient differentiation of functional hepatocytes from porcine induced pluripotent stem cells. PLOS ONE 2014, 9, e100417.

33. Hansel, M.C.; Gramignoli, R.; Blake, W.; Davila, J.; Skvorak, K.; Dorko, K.; Tahan, V.; Lee, B.R.; Tafaleng, E.; Guzman-Lepe, J.; et al. Increased reprogramming of human fetal hepatocytes compared with adult hepatocytes in feeder-free conditions. Cell Transpl. 2014, 23, 27-38.

34. Kajiwara, M.; Aoi, T.; Okita, K.; Takahashi, R.; Inoue, H.; Takayama, N.; Endo, H.; Eto, K.; Toguchida, J.; Uemoto, S.; et al. Donor-dependent variations in hepatic differentiation from human-induced pluripotent stem cells. Proc. Natl. Acad. Sci. USA 2012, 109, 12538-12543.

35. Liu, H.; Ye, Z.; Kim, Y.; Sharkis, S.; Jang, Y.Y. Generation of endoderm-derived human induced pluripotent stem cells from primary hepatocytes. Hepatology 2010, 51, 1810-1819.

36. Lee, S.B.; Seo, D.; Choi, D.; Park, K.Y.; Holczbauer, A.; Marquardt, J.U.; Conner, E.A.; Factor, V.M.; Thorgeirsson, S.S. Contribution of hepatic lineage stage-specific donor memory to the differential potential of induced mouse pluripotent stem cells. Stem Cells 2012, 30, 997-1007.

37. Basma, H.; Soto-Gutierrez, A.; Yannam, G.R.; Liu, L.; Ito, R.; Yamamoto, T.; Ellis, E.; Carson, S.D.; Sato, S.; Chen, Y.; et al. Differentiation and transplantation of human embryonic stem cell-derived hepatocytes. Gastroenterology 2009, 136, 990-999.

38. Snykers, S.; de Kock, J.; Rogiers, V.; Vanhaecke, T. In vitro differentiation of embryonic and adult stem cells into hepatocytes: State of the art. Stem Cells 2009, 27, 577-605.

39. Schwartz, R.E.; Fleming, H.E.; Khetani, S.R.; Bhatia, S.N. Pluripotent stem cell-derived hepatocyte-like cells. Biotechnol. Adv. 2014, 32, 504-513.

40. Ulvestad, M.; Nordell, P.; Asplund, A.; Rehnstrom, M.; Jacobsson, S.; Holmgren, G.; Davidson, L.; Brolen, G.; Edsbagge, J.; Bjorquist, P.; et al. Drug metabolizing enzyme and transporter protein profiles of hepatocytes derived from human embryonic and induced pluripotent stem cells. Biochem. Pharmacol. 2013, 86, 691-702.

41. Baharvand, H.; Hashemi, S.M.; Shahsavani, M. Differentiation of human embryonic stem cells into functional hepatocyte-like cells in a serum-free adherent culture condition. Differentiation 2008, 76, 465-477.

42. Tamai, M.; Yamashita, A.; Tagawa, Y. Mitochondrial development of the in vitro hepatic organogenesis model with simultaneous cardiac mesoderm differentiation from murine induced pluripotent stem cells. J. Biosci. Bioeng. 2011, 112, 495-500. 
43. Yu, Y.; Liu, H.; Ikeda, Y.; Amiot, B.P.; Rinaldo, P.; Duncan, S.A.; Nyberg, S.L. Hepatocyte-like cells differentiated from human induced pluripotent stem cells: Relevance to cellular therapies. Stem Cell Res. 2012, 9, 196-207.

44. Zhang, Q.; Yang, Y.; Zhang, J.; Wang, G.Y.; Liu, W.; Qiu, D.B.; Hei, Z.Q.; Ying, Q.L.; Chen, G.H. Efficient derivation of functional hepatocytes from mouse induced pluripotent stem cells by a combination of cytokines and sodium butyrate. Chin. Med. J. Engl. 2011, 124, 3786-3793.

45. Si-Tayeb, K.; Noto, F.K.; Nagaoka, M.; Li, J.; Battle, M.A.; Duris, C.; North, P.E.; Dalton, S.; Duncan, S.A. Highly efficient generation of human hepatocyte-like cells from induced pluripotent stem cells. Hepatology 2010, 51, 297-305.

46. Touboul, T.; Hannan, N.R.; Corbineau, S.; Martinez, A.; Martinet, C.; Branchereau, S.; Mainot, S.; Strick-Marchand, H.; Pedersen, R.; di Santo, J.; et al. Generation of functional hepatocytes from human embryonic stem cells under chemically defined conditions that recapitulate liver development. Hepatology 2010, 51, 1754-1765.

47. Song, Z.; Cai, J.; Liu, Y.; Zhao, D.; Yong, J.; Duo, S.; Song, X.; Guo, Y.; Zhao, Y.; Qin, H.; et al. Efficient generation of hepatocyte-like cells from human induced pluripotent stem cells. Cell Res. 2009, 19, 1233-1242.

48. Ma, X.; Duan, Y.; Tschudy-Seney, B.; Roll, G.; Behbahan, I.S.; Ahuja, T.P.; Tolstikov, V.; Wang, C.; McGee, J.; Khoobyari, S.; et al. Highly efficient differentiation of functional hepatocytes from human induced pluripotent stem cells. Stem Cells Transl. Med. 2013, 2, 409-419.

49. Sjogren, A.K.; Liljevald, M.; Glinghammar, B.; Sagemark, J.; Li, X.Q.; Jonebring, A.; Cotgreave, I.; Brolen, G.; Andersson, T.B. Critical differences in toxicity mechanisms in induced pluripotent stem cell-derived hepatocytes, hepatic cell lines and primary hepatocytes. Arch. Toxicol. 2014, 88, 1427-1437.

50. Si-Tayeb, K.; Lemaigre, F.P.; Duncan, S.A. Organogenesis and development of the liver. Dev. Cell 2010, 18, 175-189.

51. Aravalli, R.N.; Cressman, E.N.; Steer, C.J. Hepatic differentiation of porcine induced pluripotent stem cells in vitro. Vet. J. 2012, 194, 369-374.

52. Takata, A.; Otsuka, M.; Kogiso, T.; Kojima, K.; Yoshikawa, T.; Tateishi, R.; Kato, N.; Shiina, S.; Yoshida, H.; Omata, M.; et al. Direct differentiation of hepatic cells from human induced pluripotent stem cells using a limited number of cytokines. Hepatol. Int. 2011, 5, 890-898.

53. Tomizawa, M.; Shinozaki, F.; Sugiyama, T.; Yamamoto, S.; Sueishi, M.; Yoshida, T. Single-step protocol for the differentiation of human-induced pluripotent stem cells into hepatic progenitor-like cells. Biomed. Rep. 2013, 1, 18-22.

54. Itaba, N.; Wairagu, P.M.; Aramaki, N.; Yasui, T.; Matsumi, Y.; Kono, Y.; Phan, A.N.; Otsu, M.; Kunisada, T.; Nakamura, Y.; et al. Nuclear receptor gene alteration in human induced pluripotent stem cells with hepatic differentiation propensity. Hepatol. Res. 2014, 44, E408-E419.

55. Ninomiya, H.; Mizuno, K.; Terada, R.; Miura, T.; Ohnuma, K.; Takahashi, S.; Asashima, M.; Michiue, T. Improved efficiency of definitive endoderm induction from human induced pluripotent stem cells in feeder and serum-free culture system. Vitro. Cell. Dev. Biol. Anim. 2015, $51,1-8$. 
56. Lavon, N. Generation of hepatocytes from human embryonic stem cells. Methods Mol. Biol. 2010, 640, 237-246.

57. Zhang, R.; Takebe, T.; Sekine, K.; Koike, H.; Zheng, Y.; Taniguchi, H. Identification of proliferating human hepatic cells from human induced pluripotent stem cells. Transplant. Proc. 2014, 46, 1201-1204.

58. McLean, A.B.; D’Amour, K.A.; Jones, K.L.; Krishnamoorthy, M.; Kulik, M.J.; Reynolds, D.M.; Sheppard, A.M.; Liu, H.; Xu, Y.; Baetge, E.E.; et al. Activin a efficiently specifies definitive endoderm from human embryonic stem cells only when phosphatidylinositol 3-kinase signaling is suppressed. Stem Cells 2007, 25, 29-38.

59. Duboc, V.; Lapraz, F.; Saudemont, A.; Bessodes, N.; Mekpoh, F.; Haillot, E.; Quirin, M.; Lepage, T. Nodal and BMP2/4 pattern the mesoderm and endoderm during development of the sea urchin embryo. Development 2010, 137, 223-235.

60. Sekine, K.; Takebe, T.; Suzuki, Y.; Kamiya, A.; Nakauchi, H.; Taniguchi, H. Highly efficient generation of definitive endoderm lineage from human induced pluripotent stem cells. Transplant. Proc. 2012, 44, 1127-1129.

61. Huang, H.P.; Yu, C.Y.; Chen, H.F.; Chen, P.H.; Chuang, C.Y.; Lin, S.J.; Huang, S.T.; Chan, W.H.; Ueng, T.H.; Ho, H.N.; et al. Factors from human embryonic stem cell-derived fibroblast-like cells promote topology-dependent hepatic differentiation in primate embryonic and induced pluripotent stem cells. J. Biol. Chem. 2010, 285, 33510-33519.

62. Cvoro, A.; Devito, L.; Milton, F.A.; Noli, L.; Zhang, A.; Filippi, C.; Sakai, K.; Suh, J.H.; Dhawan, A.; Sakai, T.; et al. A thyroid hormone receptor/KLF9 axis in human hepatocytes and pluripotent stem cells. Stem Cells 2015, 33, 416-428.

63. Hoveizi, E.; Khodadadi, S.; Tavakol, S.; Karima, O.; Nasiri-Khalili, M.A. Small molecules differentiate definitive endoderm from human induced pluripotent stem cells on PCL scaffold. Appl. Biochem. Biotechnol. 2014, 173, 1727-1736.

64. Tomizawa, M.; Shinozaki, F.; Motoyoshi, Y.; Sugiyama, T.; Yamamoto, S.; Ishige, N. An optimal medium supplementation regimen for initiation of hepatocyte differentiation in human induced pluripotent stem cells. J. Cell. Biochem. 2015, 116, 1479-1489.

65. Inamura, M.; Kawabata, K.; Takayama, K.; Tashiro, K.; Sakurai, F.; Katayama, K.; Toyoda, M.; Akutsu, H.; Miyagawa, Y.; Okita, H.; et al. Efficient generation of hepatoblasts from human ES cells and iPS cells by transient overexpression of homeobox gene HEX. Mol. Ther. 2011, 19, 400-407.

66. Schwartz, R.E.; Linehan, J.L.; Painschab, M.S.; Hu, W.S.; Verfaillie, C.M.; Kaufman, D.S. Defined conditions for development of functional hepatic cells from human embryonic stem cells. Stem Cells Dev. 2005, 14, 643-655.

67. Sasaki, T.; Takahashi, S.; Numata, Y.; Narita, M.; Tanaka, Y.; Kumagai, T.; Kondo, Y.; Matsunaga, T.; Ohmori, S.; Nagata, K. Hepatocyte nuclear factor 6 activates the transcription of CYP3A4 in hepatocyte-like cells differentiated from human induced pluripotent stem cells. Drug Metab. Pharmacokinet. 2013, 28, 250-259. 
68. Takayama, K.; Inamura, M.; Kawabata, K.; Sugawara, M.; Kikuchi, K.; Higuchi, M.; Nagamoto, Y.; Watanabe, H.; Tashiro, K.; Sakurai, F.; et al. Generation of metabolically functioning hepatocytes from human pluripotent stem cells by FOXA2 and HNF1 $\alpha$ transduction. J. Hepatol. 2012, 57, 628-636.

69. Takayama, K.; Inamura, M.; Kawabata, K.; Katayama, K.; Higuchi, M.; Tashiro, K.; Nonaka, A.; Sakurai, F.; Hayakawa, T.; Furue, M.K.; et al. Efficient generation of functional hepatocytes from human embryonic stem cells and induced pluripotent stem cells by HNF4 $\alpha$ transduction. Mol. Ther. 2012, 20, 127-137.

70. Umeda, K.; Suzuki, K.; Yamazoe, T.; Shiraki, N.; Higuchi, Y.; Tokieda, K.; Kume, K.; Mitani, K.; Kume, S. Albumin gene targeting in human embryonic stem cells and induced pluripotent stem cells with helper-dependent adenoviral vector to monitor hepatic differentiation. Stem Cell Res. 2013, 10, 179-194.

71. Xing, Q.; Luo, Y.; Gao, Y.; Zhang, S.; Zhu, Z.; Wang, Y.; Yuan, Q.; Shu, G.; Lou, C.; Wang, J.; et al. Hepatectomised patient sera promote hepatocyte differentiation of human-induced pluripotent stem cells. Dig. Liver Dis. 2014, 46, 731-737.

72. Shan, J.; Schwartz, R.E.; Ross, N.T.; Logan, D.J.; Thomas, D.; Duncan, S.A.; North, T.E.; Goessling, W.; Carpenter, A.E.; Bhatia, S.N. Identification of small molecules for human hepatocyte expansion and iPS differentiation. Nat. Chem. Biol. 2013, 9, 514-520.

73. Kondo, Y.; Iwao, T.; Yoshihashi, S.; Mimori, K.; Ogihara, R.; Nagata, K.; Kurose, K.; Saito, M.; Niwa, T.; Suzuki, T.; et al. Histone deacetylase inhibitor valproic acid promotes the differentiation of human induced pluripotent stem cells into hepatocyte-like cells. PLoS ONE 2014, 9, e104010.

74. Kondo, Y.; Yoshihashi, S.; Mimori, K.; Ogihara, R.; Kanehama, Y.; Maki, Y.; Enosawa, S.; Kurose, K.; Iwao, T.; Nakamura, K.; et al. Selective culture method for hepatocyte-like cells differentiated from human induced pluripotent stem cells. Drug Metab. Pharmacokinet. 2014, 29, 407-413.

75. Avior, Y.; Levy, G.; Zimerman, M.; Kitsberg, D.; Schwartz, R.; Sadeh, R.; Moussaieff, A.; Cohen, M.; Itskovitz-Eldor, J.; Nahmias, Y. Microbial-derived lithocholic acid and vitamin K2 drive the metabolic maturation of pluripotent stem cells-derived and fetal hepatocytes. Hepatology 2015, 62, 265-278.

76. Siller, R.; Greenhough, S.; Naumovska, E.; Sullivan, G.J. Small-molecule-driven hepatocyte differentiation of human pluripotent stem cells. Stem Cell Rep. 2015, 4, 939-952.

77. Ishikawa, T.; Kobayashi, M.; Yanagi, S.; Kato, C.; Takashima, R.; Kobayashi, E.; Hagiwara, K.; Ochiya, T. Human induced hepatic lineage-oriented stem cells: Autonomous specification of human iPS cells toward hepatocyte-like cells without any exogenous differentiation factors. PLoS ONE 2015, 10, e0123193.

78. Wang, Y.; Yao, H.L.; Cui, C.B.; Wauthier, E.; Barbier, C.; Costello, M.J.; Moss, N.; Yamauchi, M.; Sricholpech, M.; Gerber, D.; et al. Paracrine signals from mesenchymal cell populations govern the expansion and differentiation of human hepatic stem cells to adult liver fates. Hepatology 2010, 52, 1443-1454.

79. So, J.; Martin, B.L.; Kimelman, D.; Shin, D. Wnt/ $\beta$-catenin signaling cell-autonomously converts non-hepatic endodermal cells to a liver fate. Biol. Open 2013, 2, 30-36. 
80. Ungrin, M.D.; Joshi, C.; Nica, A.; Bauwens, C.; Zandstra, P.W. Reproducible, ultra high-throughput formation of multicellular organization from single cell suspension-derived human embryonic stem cell aggregates. PLOS ONE 2008, 3, e1565.

81. Lau, T.T.; Ho, L.W.; Wang, D.A. Hepatogenesis of murine induced pluripotent stem cells in 3D micro-cavitary hydrogel system for liver regeneration. Biomaterials 2013, 34, 6659-6669.

82. Yamazoe, T.; Shiraki, N.; Kume, S. Hepatic differentiation from murine and human iPS cells using nanofiber scaffolds. Methods Mol. Biol. 2014, doi:10.1007/7651_2014_138.

83. Zhang, R.R.; Takebe, T.; Miyazaki, L.; Takayama, M.; Koike, H.; Kimura, M.; Enomura, M.; Zheng, Y.W.; Sekine, K.; Taniguchi, H. Efficient hepatic differentiation of human induced pluripotent stem cells in a three-dimensional microscale culture. Methods Mol. Biol. 2014, 1210, 131-141.

84. Vosough, M.; Omidinia, E.; Kadivar, M.; Shokrgozar, M.A.; Pournasr, B.; Aghdami, N.; Baharvand, H. Generation of functional hepatocyte-like cells from human pluripotent stem cells in a scalable suspension culture. Stem Cells Dev. 2013, 22, 2693-2705.

85. Iwamuro, M.; Shiraha, H.; Nakaji, S.; Furutani, M.; Kobayashi, N.; Takaki, A.; Yamamoto, K. A preliminary study for constructing a bioartificial liver device with induced pluripotent stem cell-derived hepatocytes. Biomed. Eng. Online 2012, 11, 93.

86. Gieseck, R.L., 3rd; Hannan, N.R.; Bort, R.; Hanley, N.A.; Drake, R.A.; Cameron, G.W.; Wynn, T.A.; Vallier, L. Maturation of induced pluripotent stem cell derived hepatocytes by 3D-culture. PLoS ONE 2014, 9, e86372.

87. Berger, D.R.; Ware, B.R.; Davidson, M.D.; Allsup, S.R.; Khetani, S.R. Enhancing the functional maturity of induced pluripotent stem cell-derived human hepatocytes by controlled presentation of cell-cell interactions in vitro. Hepatology 2015, 61, 1370-1381.

88. Ogawa, S.; Surapisitchat, J.; Virtanen, C.; Ogawa, M.; Niapour, M.; Sugamori, K.S.; Wang, S.; Tamblyn, L.; Guillemette, C.; Hoffmann, E.; et al. Three-dimensional culture and cAMP signaling promote the maturation of human pluripotent stem cell-derived hepatocytes. Development 2013, 140, 3285-3296.

89. Takayama, K.; Nagamoto, Y.; Mimura, N.; Tashiro, K.; Sakurai, F.; Tachibana, M.; Hayakawa, T.; Kawabata, K.; Mizuguchi, H. Long-term self-renewal of human ES/iPS-derived hepatoblast-like cells on human laminin 111-coated dishes. Stem Cell Rep. 2013, 1, 322-335.

90. Takebe, T.; Zhang, R.R.; Koike, H.; Kimura, M.; Yoshizawa, E.; Enomura, M.; Koike, N.; Sekine, K.; Taniguchi, H. Generation of a vascularized and functional human liver from an iPSC-derived organ bud transplant. Nat. Protoc. 2014, 9, 396-409.

91. Takebe, T.; Sekine, K.; Enomura, M.; Koike, H.; Kimura, M.; Ogaeri, T.; Zhang, R.R.; Ueno, Y.; Zheng, Y.W.; Koike, N.; et al. Vascularized and functional human liver from an iPSC-derived organ bud transplant. Nature 2013, 499, 481-484.

92. Graf, T.; Enver, T. Forcing cells to change lineages. Nature 2009, 462, 587-594.

93. Zhu, S.; Rezvani, M.; Harbell, J.; Mattis, A.N.; Wolfe, A.R.; Benet, L.Z.; Willenbring, H.; Ding, S. Mouse liver repopulation with hepatocytes generated from human fibroblasts. Nature 2014, 508, 93-97. 
94. Du, Y.; Wang, J.; Jia, J.; Song, N.; Xiang, C.; Xu, J.; Hou, Z.; Su, X.; Liu, B.; Jiang, T.; et al. Human hepatocytes with drug metabolic function induced from fibroblasts by lineage reprogramming. Cell Stem Cell 2014, 14, 394-403.

95. Huang, P.; He, Z.; Ji, S.; Sun, H.; Xiang, D.; Liu, C.; Hu, Y.; Wang, X.; Hui, L. Induction of functional hepatocyte-like cells from mouse fibroblasts by defined factors. Nature 2011, 475, 386-389.

96. Sekiya, S.; Suzuki, A. Direct conversion of mouse fibroblasts to hepatocyte-like cells by defined factors. Nature 2011, 475, 390-393.

97. Simeonov, K.P.; Uppal, H. Direct reprogramming of human fibroblasts to hepatocyte-like cells by synthetic modified mRNAs. PLoS ONE 2014, 9, e100134.

98. Zhang, Z.; Gong, Y.; Guo, Y.; Hai, Y.; Yang, H.; Yang, S.; Liu, Y.; Ma, M.; Liu, L.; Li, Z.; et al. Direct transdifferentiation of spermatogonial stem cells to morphological, phenotypic and functional hepatocyte-like cells via the ERK1/2 and Smad2/3 signaling pathways and the inactivation of cyclin A, cyclin B and cyclin E. Cell Commun. Signal. 2013, 11, 67.

99. Cantz, T.; Bleidissel, M.; Stehling, M.; Scholer, H.R. In vitro differentiation of reprogrammed murine somatic cells into hepatic precursor cells. Biol. Chem. 2008, 389, 889-896.

100. Chiang, C.H.; Chang, C.C.; Huang, H.C.; Chen, Y.J.; Tsai, P.H.; Jeng, S.Y.; Hung, S.I.; Hsieh, J.H.; Huang, H.S.; Chiou, S.H.; et al. Investigation of hepatoprotective activity of induced pluripotent stem cells in the mouse model of liver injury. J. Biomed. Biotechnol. 2011, 2011, 219060.

101. Liu, H.; Kim, Y.; Sharkis, S.; Marchionni, L.; Jang, Y.Y. In vivo liver regeneration potential of human induced pluripotent stem cells from diverse origins. Sci. Transl. Med. 2011, 3, 82ra39, doi:10.1126/scitranslmed.3002376.

102. Chen, Y.; Li, Y.; Wang, X.; Zhang, W.; Sauer, V.; Chang, C.J.; Han, B.; Tchaikovskaya, T.; Avsar, Y.; Tafaleng, E.; et al. Amelioration of hyperbilirubinemia in gunn rats after transplantation of human induced pluripotent stem cell-derived hepatocytes. Stem Cell Rep. 2015, 5, 22-30.

103. Balasiddaiah, A.; Moreno, D.; Guembe, L.; Prieto, J.; Aldabe, R. Hepatic differentiation of mouse iPS cells and analysis of liver engraftment potential of multistage iPS progeny. J. Physiol. Biochem. 2013, 69, 835-845.

104. Nagamoto, Y.; Takayama, K.; Tashiro, K.; Tateno, C.; Sakurai, F.; Tachibana, M.; Kawabata, K.; Ikeda, K.; Tanaka, Y.; Mizuguchi, H. Efficient engraftment of human induced pluripotent stem cell-derived hepatocyte-like cells in uPA/SCID mice by overexpression of FNK, a Bcl-xL mutant gene. Cell Transplant. 2015, 24, 1127-1138.

105. Chan, C.C.; Cheng, L.Y.; Lu, J.; Huang, Y.H.; Chiou, S.H.; Tsai, P.H.; Huo, T.I.; Lin, H.C.; Lee, F.Y. The role of interferon- $\gamma$ inducible protein-10 in a mouse model of acute liver injury post induced pluripotent stem cells transplantation. PLOS ONE 2012, 7, e50577.

106. Chang, H.M.; Liao, Y.W.; Chiang, C.H.; Chen, Y.J.; Lai, Y.H.; Chang, Y.L.; Chen, H.L.; Jeng, S.Y.; Hsieh, J.H.; Peng, C.H.; et al. Improvement of carbon tetrachloride-induced acute hepatic failure by transplantation of induced pluripotent stem cells without reprogramming factor c-Myc. Int. J. Mol. Sci. 2012, 13, 3598-3617.

107. Li, H.Y.; Chien, Y.; Chen, Y.J.; Chen, S.F.; Chang, Y.L.; Chiang, C.H.; Jeng, S.Y.; Chang, C.M.; Wang, M.L.; Chen, L.K.; et al. Reprogramming induced pluripotent stem cells in the absence of c-Myc for differentiation into hepatocyte-like cells. Biomaterials 2011, 32, 5994-6005. 
108. Chien, Y.; Chang, Y.L.; Li, H.Y.; Larsson, M.; Wu, W.W.; Chien, C.S.; Wang, C.Y.; Chu, P.Y.; Chen, K.H.; Lo, W.L.; et al. Synergistic effects of carboxymethyl-hexanoyl chitosan, cationic polyurethane-short branch PEI in miR122 gene delivery: Accelerated differentiation of iPSCs into mature hepatocyte-like cells and improved stem cell therapy in a hepatic failure model. Acta Biomater. 2015, 13, 228-244.

109. Van Wenum, M.; Chamuleau, R.A.; van Gulik, T.M.; Siliakus, A.; Seppen, J.; Hoekstra, R. Bioartificial livers in vitro and in vivo: Tailoring biocomponents to the expanding variety of applications. Expert Opin. Biol. Ther. 2014, 14, 1745-1760.

110. Taapken, S.M.; Nisler, B.S.; Newton, M.A.; Sampsell-Barron, T.L.; Leonhard, K.A.; McIntire, E.M.; Montgomery, K.D. Karotypic abnormalities in human induced pluripotent stem cells and embryonic stem cells. Nat. Biotechnol. 2011, 29, 313-314.

111. Mekhoubad, S.; Bock, C.; de Boer, A.S.; Kiskinis, E.; Meissner, A.; Eggan, K. Erosion of dosage compensation impacts human iPSC disease modeling. Cell Stem Cell 2012, 10, 595-609.

112. Marchetto, M.C.; Carromeu, C.; Acab, A.; Yu, D.; Yeo, G.W.; Mu, Y.; Chen, G.; Gage, F.H.; Muotri, A.R. A model for neural development and treatment of Rett syndrome using human induced pluripotent stem cells. Cell 2010, 143, 527-539.

113. Chaerkady, R.; Kerr, C.L.; Kandasamy, K.; Marimuthu, A.; Gearhart, J.D.; Pandey, A. Comparative proteomics of human embryonic stem cells and embryonal carcinoma cells. Proteomics 2010, 10, 1359-1373.

114. Habib, O.; Habib, G.; Choi, H.W.; Hong, K.S.; Do, J.T.; Moon, S.H.; Chung, H.M. An improved method for the derivation of high quality iPSCs in the absence of c-Myc. Exp. Cell Res. 2013, 319, 3190-3200.

115. Noto, F.K.; Determan, M.R.; Cai, J.; Cayo, M.A.; Mallanna, S.K.; Duncan, S.A. Aneuploidy is permissive for hepatocyte-like cell differentiation from human induced pluripotent stem cells. BMC Res. Notes 2014, 7, 437, doi:10.1186/1756-0500-7-437.

116. Sullivan, G.J.; Hay, D.C.; Park, I.H.; Fletcher, J.; Hannoun, Z.; Payne, C.M.; Dalgetty, D.; Black, J.R.; Ross, J.A.; Samuel, K.; et al. Generation of functional human hepatic endoderm from human induced pluripotent stem cells. Hepatology 2010, 51, 329-335.

117. Lu, J.; Einhorn, S.; Venkatarangan, L.; Miller, M.; Mann, D.A.; Watkins, P.B.; LeCluyse, E. Morphological and functional characterization and assessment of iPSC-derived hepatocytes for in vitro toxicity testing. Toxicol. Sci. 2015, doi:10.1093/toxsci/kfv117.

118. Yoshida, T.; Takayama, K.; Kondoh, M.; Sakurai, F.; Tani, H.; Sakamoto, N.; Matsuura, Y.; Mizuguchi, H.; Yagi, K. Use of human hepatocyte-like cells derived from induced pluripotent stem cells as a model for hepatocytes in hepatitis $\mathrm{C}$ virus infection. Biochem. Biophys. Res. Commun. 2011, 416, 119-124.

119. Rashid, S.T.; Corbineau, S.; Hannan, N.; Marciniak, S.J.; Miranda, E.; Alexander, G.; Griffin, J.; Huang-Doran, I.; Ahrlund-Richter, L.; Skepper, J.; et al. Modeling inherited metabolic disorders of the liver using human induced pluripotent stem cells. J. Clin. Investig. 2010, 120, 3127-3136.

120. Wilson, A.A.; Ying, L.; Liesa, M.; Segeritz, C.P.; Mills, J.A.; Shen, S.S.; Jean, J.; Lonza, G.C.; Liberti, D.C.; Lang, A.H.; et al. Emergence of a stage-dependent human liver disease signature with directed differentiation of $\alpha-1$ antitrypsin-deficient iPS cells. Stem Cell Rep. 2015, 4, $873-885$. 
121. Choi, S.M.; Kim, Y.; Shim, J.S.; Park, J.T.; Wang, R.H.; Leach, S.D.; Liu, J.O.; Deng, C.; Jang, Y.Y.; Ye, Z. Efficient drug screening and gene correction for treating liver disease using patient-specific stem cells. Hepatology 2013, 57, 2458-2468.

122. Yi, F.; Qu, J.; Li, M.; Suzuki, K.; Kim, N.Y.; Liu, G.H.; Belmonte, J.C. Establishment of hepatic and neural differentiation platforms of Wilson's disease specific induced pluripotent stem cells. Protein Cell 2012, 3, 855-863.

123. Soldner, F.; Laganiere, J.; Cheng, A.W.; Hockemeyer, D.; Gao, Q.; Alagappan, R.; Khurana, V.; Golbe, L.I.; Myers, R.H.; Lindquist, S.; et al. Generation of isogenic pluripotent stem cells differing exclusively at two early onset Parkinson point mutations. Cell 2011, 146, 318-331.

124. Cayo, M.A.; DeLaForest, A.; Noto, F.K.; Nagaoka, M.; Clark, B.S.; Collery, R.F.; Si-Tayeb, K.; Cai, J.; Duncan, S.A. JD induced pluripotent stem cell-derived hepatocytes faithfully recapitulate the pathophysiology of familial hypercholesterolemia. Hepatology 2012, 56, 2163-2171.

125. Zhou, X.L.; Sullivan, G.J.; Sun, P.; Park, I.H. Humanized murine model for HBV and HCV using human induced pluripotent stem cells. Arch. Pharm. Res. 2012, 35, 261-269.

(C) 2015 by the authors; licensee MDPI, Basel, Switzerland. This article is an open access article distributed under the terms and conditions of the Creative Commons Attribution license (http://creativecommons.org/licenses/by/4.0/). 